\title{
18. MAGNETIZATION OF THE OCEANIC CRUST INFERRED FROM MAGNETIC LOGGING IN HOLE 395A 1
}

\author{
Yozo Hamano 2 and Hajimu Kinoshita ${ }^{3}$
}

\begin{abstract}
Three components of the magnetic field in Hole 395A have been measured by a newly developed magnetometer. Observed variations of the vertical and the horizontal components of the magnetic field were interpreted by use of simple model calculations. The results indicate that the size of the homogeneously magnetized body around the hole is about $100 \mathrm{~m}$, and that the normal-reverse boundary observed at $260 \mathrm{~m}$ sub-bottom depth in Hole $395 \mathrm{~A}$ is tilted in an east-west direction by about $30^{\circ}$.
\end{abstract}

\section{INTRODUCTION}

Downhole measurements of the magnetic field within ODP and DSDP holes can be a useful counterpart to the paleomagnetic study of recovered rock samples from these holes, in order to obtain an insight into the nature of the magnetic structure of the oceanic crust. In Hole 395A, the vertical component of the magnetic field was measured during Leg 76B (Ponomarev and Nechoroshkov, 1984). However, measurement of all three components of the magnetic field would provide more information about the nature of the young oceanic cruet surrounding the hole. During Leg 109, three types of magnetometers were used for magnetic logging in this hole. These three magnetometers gave very consistent results on the variation of the magnetic field within the hole. One of them was a self-contained high-temperature three-component borehole magnetometer, which had been developed in Japan recently. In the present paper, the magnetic properties of the rocks around the hole inferred from magnetic logging will be discussed.

\section{VARIATION OF THE MAGNETIC FIELD IN HOLE 395A}

The 3-component magnetometer and the measurement are fully explained in Detrick, Honnorez, Bryan, Juteau, et al. (1988). The magnetometer measures the three components of the magnetic field and the temperature. Downhole measurements of the magnetic field were made with this apparatus on 7 June 1988. The operation was combined with the MCS (Multichannel Sonic) measurement. The magnetometer was attached to the bottom of the MCS logging tool, and both instruments were lowered together by a cable. The selfcontained nature of the magnetometer (no cable for the power and signal transmission) enabled this combined experiment.

The magnetic field measurements were made with this instrument while the tools were going up the hole at a speed of $2 \mathrm{~m} / \mathrm{min}$. Since the magnetometer measures the signal every $30 \mathrm{~s}$, the sampling interval at this speed was $1 \mathrm{~m}$. The magnetometer measured the three components of the magnetic field and the temperature within Hole 395A from $600 \mathrm{~m}$ to $112 \mathrm{~m}$ sub-bottom depth. From the observed three compo-

\footnotetext{
${ }^{1}$ Detrick, R., Honnorez, J., Bryan, W. B., Juteau, T., et al., 1990. Proc. ODP, Init. Repts., 106/109: College Station, TX (Ocean Drilling Program).

${ }^{2}$ Earthquake Research Institute, University of Tokyo, Bunkyo-ku, Tokyo 113, Japan.

${ }^{3}$ Faculty of Science, Chiba University, Chiba-shi, Chiba 260, Japan.
}

nents of the magnetic field, the magnetic total force, the horizontal component, the vertical component, and the inclination of the magnetic field inside the hole were calculated. The variation of the horizontal and the vertical components of the magnetic field are shown in Figure 1. The following interpretation is based mainly on the variations of these two components.

The most prominent feature in the variation of the magnetic field is the sharp jump observed at about $260 \mathrm{~m}$ sub-bottom depth. At the jump, the vertical field increases by about 7000 nT and the horizontal field decreases by about the same amount. The depths of the jumps are closely correlated with the transitions of the magnetization of the basalt rocks, which were observed from the paleomagnetic study of the rocks recovered from Hole 395A during Leg 45 (Johnson, 1978). The basalts recovered above $256 \mathrm{~m}$ sub-bottom depth are normally magnetized, and those below that level are reversely magnetized. The sense of the jump is consistent with the expected reversals based on paleomagnetic studies of cores made during DSDP Leg 45. Another small jump is observed at about $570 \mathrm{~m}$ sub-bottom depth where the amount of the jump is much smaller and in the opposite sense compared to the upper boundary. This jump also corresponds to the reverse to normal transition observed in the study of the recovered rock samples.

Besides the jumps noted above, the variation of the magnetic field has high frequency components with an approximate wavelength of $5 \mathrm{~m}$. These features are very consistent with the results of the German magnetometer log made during Leg 109, which is reported by Bosom and Kopietz (this volume). The same feature obtained by the different logs suggests that the high frequency variation is real and represents the actual variation of the magnetic field within this hole.

Long wavelength variation of the magnetic field shows a systematic decay of the magnetic field to the mean value in the regions below and above the upper boundary. Although both the vertical and the horizontal field show this tendency, the characteristic decay length in the vertical direction is about $150 \mathrm{~m}$ with the decay rate of about $100 \mathrm{nT} / 100 \mathrm{~m}$, whereas that in the horizontal direction is much shorter with a length of about $50 \mathrm{~m}$. The lower boundary is too close to the bottom of the hole to investigate such long wavelength variations.

In the present paper, we explain the relative amount of the field jump at the upper boundary and the long wavelength variation on both sides of the boundary in terms of the heterogeneity of the magnetic structure around the hole. Since the paleomagnetic study on the recovered samples from Hole 
395A (Johnson, 1978), do not show a systematic variation of the magnetization along the hole besides the polarity change at $260 \mathrm{~m}$ sub-bottom depth, we need to take into account the horizontal variation of the magnetization. The results of the inversion of the logging data including the short wavelength variation will be given in a separate paper being prepared by Hamano.

\section{HORIZONTAL BOUNDARY MODEL}

As a starting model for the interpretation of the present data, we first assume that the cross section of the hole is a perfect circle, and that a cylindrical region around the hole is homogeneously magnetized. In this model, the magnetic field at the center of the hole can be easily calculated. The vertical and the horizontal field at $\mathrm{z}=\mathrm{z}_{\mathrm{o}}$ due to the magnetized body bounded by $\mathrm{z}=\mathrm{z}_{1}$ and $\mathrm{z}_{2}$ can be expressed as

$$
\begin{aligned}
& \mathrm{H} / \mathrm{m}=\pi \cos \mathrm{I} \frac{\mathrm{z}_{\mathrm{o}}-\mathrm{z}}{\sqrt{\left(\mathrm{z}_{\mathrm{o}}-\mathrm{z}\right)^{2}+\mathrm{R}^{2}}}\left|\begin{array}{l}
\mathrm{z}_{2} \\
\mathrm{z}_{1}
\end{array}\right| \mathrm{R}_{2} \\
& \mathrm{Z} / \mathrm{m}=-2 \pi \sin \mathrm{I} \frac{\mathrm{z}_{\mathrm{o}}-\mathrm{z}}{\sqrt{\left(\mathrm{z}_{\mathrm{o}}-\mathrm{z}\right)^{2}+\mathrm{R}^{2}}}\left|\begin{array}{l}
\mathrm{z}_{2} \\
\mathrm{z}_{1}
\end{array}\right| \mathrm{R}_{1}
\end{aligned}
$$

where $\mathrm{m}$ is the intensity of the magnetization, $\mathrm{I}$ is the inclination of the magnetization, and $R_{1}=r$ and $R_{2}=R$ denote the radii of the hole and the cylindrical magnetized body, respectively. And the notation convention of

$$
\mathrm{f}(\mathrm{x}, \mathrm{y}) \mid \begin{array}{l|l}
\mathrm{x}_{2} & \mathrm{y}_{2} \\
\mathrm{x}_{1} & \mathrm{y}_{1}
\end{array}=\mathrm{f}\left(\mathrm{x}_{2}, \mathrm{y}_{2}\right)-\mathrm{f}\left(\mathrm{x}_{2}, \mathrm{y}_{1}\right)-\mathrm{f}\left(\mathrm{x}_{1}, \mathrm{y}_{2}\right)+\mathrm{f}\left(\mathrm{x}_{1}, \mathrm{y}_{1}\right)
$$

is used.

For the comparison with the observed data, we consider an infinitely long hole extending along the vertical $(\mathrm{z})$ direction. The region around the hole bounded by a cylindrical surface with a radius of $\mathrm{R}$ is magnetized, where the region with positive $\mathrm{z}$ is reversely magnetized and the region with negative $\mathrm{z}$ is normally magnetized. Hence, the $\mathrm{z}=0$ surface is the boundary of the normally and the reversely magnetized regions. The results of the calculation by using the above equation for $\mathrm{r}=15 \mathrm{~cm}$ and $\mathrm{R}=10 \mathrm{~m}, 30 \mathrm{~m}, 100 \mathrm{~m}$, and $300 \mathrm{~m}$ are shown in Figure 2, where the inclination of the magnetization was assumed to be $45^{\circ}$ which is close to the inclination of the present geomagnetic field. The result suggests that the sense of the observed jump is consistent with the normal to reverse transition at the boundary observed from the study of the recovered basalt cores, and the results of the model calculation explain the main feature of the observed variation of the magnetic field. However, some features in the model calculation do not match the observed data. In the calculated variation of the magnetic field, the amount of the jump at the boundary in the vertical direction is twice as large as that in the horizontal direction, whereas the amount of jump in the observed field is very similar in both directions. Since the amount does not depend on the radius of the magnetized body as shown in Figure 2, this can not be explained by the radius of the magnetized body around the hole. The model clearly shows that the magnetic field decays to zero on both sides of the boundary, and the decay rate depends on the size of the magnetized body expressed by $\mathrm{R}$. The slower decay rate is observed for the larger magnetized body. The characteristic length of the decay along the vertical direction, defined as a distance from the boundary where the magnetic field becomes $1 / \mathrm{e}$ of the value at the boundary, is very similar to the radius of the magnetized cylindrical body, and the length is the same for the vertical and the horizontal directions. These results can be used to estimate the size of the magnetized region around Hole 395 from the observed data. However, the extent of the magnetized body estimated from the variation of the vertical field (about $150 \mathrm{~m}$ ) is considerably different from that estimated from the horizontal field (about $50 \mathrm{~m}$ ).

As explained above, the similarity of the amount of the jump at the boundary in the vertical and the horizontal directions and the difference of the characteristic length of the decay on both sides of the boundary between the two directions can not be explained by the present horizontal boundary model, although the main features of the observed variation are qualitatively explained by this simple model. The former discrepancy can be explained by assuming a shallow inclination of the magnetization around Hole 395A. But this assumption contradicts the observed inclination of the rock samples recovered from the hole (Johnson, 1978), and the second discrepancy is still to be explained.

\section{TILTED BOUNDARY MODEL}

In the previous section, a simple model calculation was made and compared with the observed data, where the boundary between the upper normally magnetized region and the lower reversely magnetized region was assumed to be horizontal. However, the model cannot fully explain the features observed in Hole 395A.

In the following section, we investigate the effect of the tilted boundary on the variation of the magnetic field observed along the hole. For this purpose, the circular hole model cannot give an analytical formula for the magnetic field. Hence, a rectangular hole model is considered, where the magnetized region around the hole is also assumed to have a rectangular cross section. Before calculating the field variation based on the tilted boundary model, we calculate the horizontal boundary case for the rectangular hole model in order to estimate the effect of the shape of the hole on the variation. The result can be expressed as

$$
\begin{gathered}
H / m=\left.\left.4 \cos I \tan ^{-1}\left(\frac{z_{o}-z}{\sqrt{\left(z_{o}-z\right)^{2}+2 d^{2}}}\right)\right|_{z_{1}} ^{z_{2}}\right|_{1} ^{d_{2}} \\
Z / m=4 \sin I \tan ^{-1}\left(\frac{d^{2}}{\left(z_{o}-z\right) \sqrt{\left(z_{o}-z\right)^{2}+2 d^{2}}}\right)\left|z_{z_{1}}^{z_{2}}\right|_{d_{1}}^{d_{2}}
\end{gathered}
$$

where $d_{1}$ and $d_{2}$ denote the length of the side of the hole and the magnetized region. Comparison of the above equations with the circular hole case discussed before indicates that the overall features such as the amount of the jump at the boundary and the decay of the magnetic field around the boundary are very similar in both cases. Hence, the difference of the shape of the hole and the magnetized region do not 

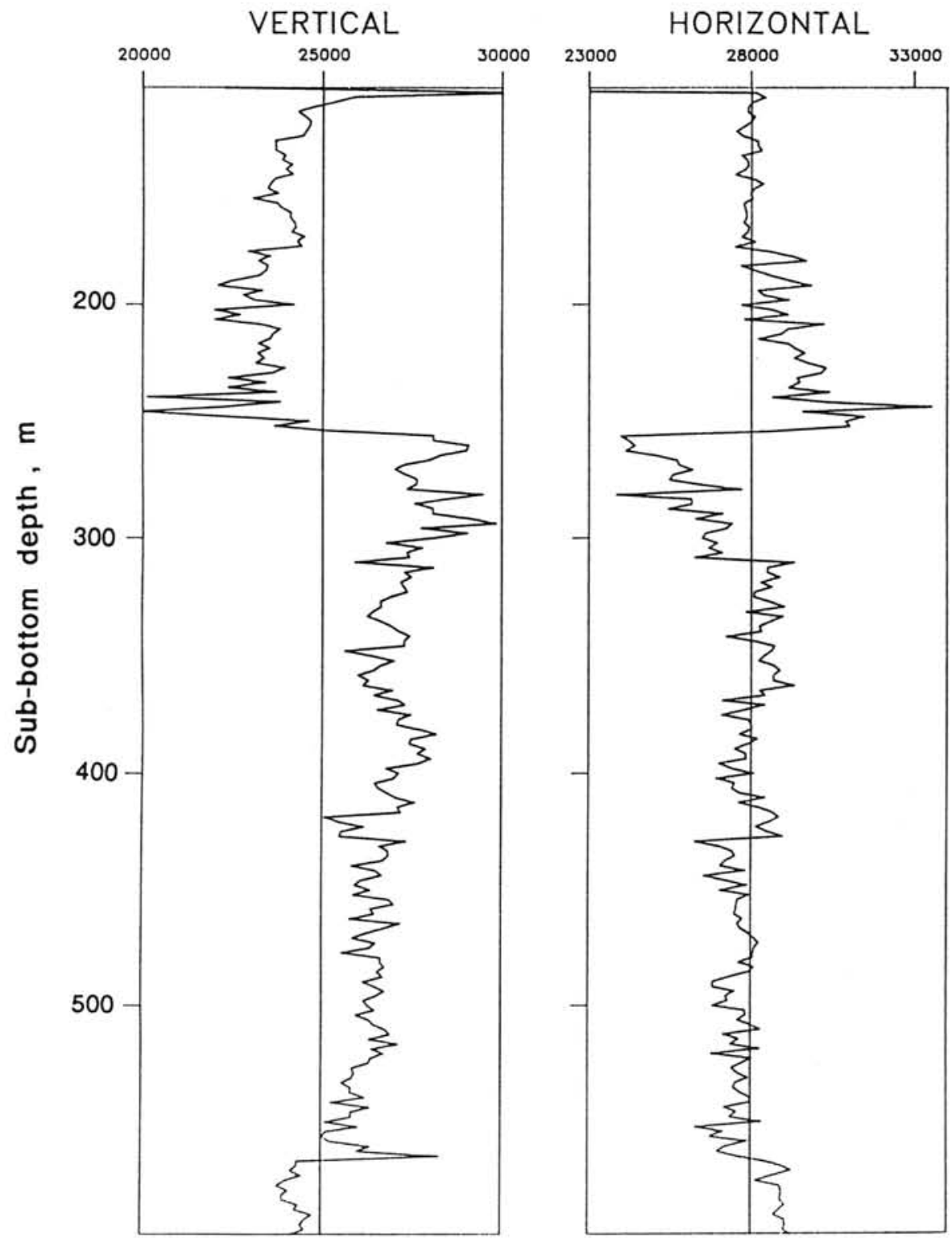

Figure 1. Depth variation of the vertical and the horizontal components of the magnetic field in Hole 395A.

significantly affect the calculated variation of the magnetic field.

For the calculation of the magnetic field in the tilted boundary model, lengthy calculations of the integration and the modification of the formula are necessary. In the present paper, only the final equations are shown, and the main feature of the variation of the magnetic field is discussed. The process for the derivation of the formulas and the detailed calculation based on the equations are given in a separate paper being prepared by Hamano.

The configuration of the tilted boundary model is shown in Figure 3, where we assume that the orientation of the magnetization is in the north direction $(\mathrm{x})$ with the inclination $\mathrm{I}$, and the magnetizations in the normal and the reversed directions are exactly opposite. The tilted boundary is characterized by the dip direction $\mathrm{D}$ measured from the $\mathrm{x}$-axis and the dip angle $\alpha$. The magnetized body around the hole is bounded by a rectangular cylindrical surface with the length of the side, d.
Then, the three components of the magnetic field in the hole are expressed as

$$
\begin{gathered}
\mathrm{H}_{\mathrm{x}} / \mathrm{m}=2 \cos \mathrm{I} \cos \mathrm{D}\left(\mathrm{M}-2 \tan ^{-1}\left(\frac{\mathrm{Z}}{|\mathrm{z}|}\right)\right)-\frac{1}{1+\mathrm{a}^{2}} \\
(\mathrm{a} \cos \mathrm{I} \cos \mathrm{D}-\sin \mathrm{I})(\mathrm{L}-2 \mathrm{aK}) \\
\mathrm{H}_{\mathrm{y}} / \mathrm{m}=2 \cos \mathrm{I} \sin \mathrm{D}\left(\frac{\mathrm{z}}{|\mathrm{z}|} \mathrm{N}-2 \tan ^{-1}\left(\frac{\mathrm{Z}}{|\mathrm{z}|}\right)\right) \\
\mathrm{H}_{\mathrm{z}} / \mathrm{m}=\frac{1}{1+\mathrm{a}^{2}} \mid\{2(\mathrm{a} \cos \mathrm{I} \cos \mathrm{D}-\sin \mathrm{I}) \mathrm{K} \\
-(\cos \mathrm{I} \cos \mathrm{D}+\mathrm{a} \sin \mathrm{I}) \mathrm{L}\}
\end{gathered}
$$


and

$$
\begin{gathered}
K=\tan ^{-1}\left(\frac{a z-\left(1+a^{2}\right)}{z \sqrt{\left(z-a^{2}\right)+2}}\right)-\tan ^{-1}\left(\frac{a z+\left(1+a^{2}\right)}{z \sqrt{\left(z+a^{2}+2\right.}}\right) \\
L=\log \left|\frac{\sqrt{(z-a)^{2}+2}-1}{\sqrt{(z-a)^{2}+2}+1}\right|-\log \frac{\sqrt{(z+a)^{2}+2}-1}{\sqrt{(z+a)^{2}+2}+1} \mid \\
M=\tan ^{-1}\left(\frac{z-a}{\sqrt{(z-a)^{2}+2}}\right)+\tan ^{-1}\left(\frac{z+a}{\sqrt{(z-a)^{2}+2}}\right) \\
N=\frac{z-a}{|z-a|} \tan ^{-1}\left(\frac{z+a}{\sqrt{(z-a)^{2}+2}}\right) \\
+\frac{z+a}{|z+a|} \tan ^{-1}\left(\frac{z-a}{\sqrt{(z+a)^{2}+2}}\right)
\end{gathered}
$$

where $\mathrm{a}=\tan \alpha$ and $\mathrm{z}=\mathrm{z}_{\mathrm{o}} / \mathrm{d}$. The three components of the magnetic field have to be calculated, since the y component of the magnetic field becomes non-zero due to the tilt of the boundary even though the magnetization is in the $\mathrm{x}$ direction.
The horizontal intensity of the magnetic field is calculated by

$$
\mathrm{H} / \mathrm{m}=\sqrt{\left(\mathrm{H}_{\mathrm{x}} / \mathrm{m}\right)^{2}+\left(\mathrm{H}_{\mathrm{y}} / \mathrm{m}\right)^{2}}
$$

The above equations can be used to calculate the magnetic field at the center of the hole for any configuration of the tilted boundary. Figure 4 shows the effect of the tilt on the variation of the vertical and the horizontal components of the magnetic field, in which the magnetization of the surrounding rocks is in the horizontal direction. The calculated variations for tilt angles of $0^{\circ}, 10^{\circ} \cdot 20^{\circ}$, and $30^{\circ}$ in the $\mathrm{x}$ direction are shown in Figure 4. In this example there is no vertical component of the magnetization, and therefore the vertical magnetic field due to the magnetization is zero throughout the hole for the case in which the normal-reverse boundary is horizontal (tilt angle $=$ $0^{\circ}$ ). As the tilt angle increases, the vertical magnetic field is no longer zero, and becomes larger as the angle increases. Also, the jump of the vertical magnetic field at the boundary has the same sense as that of the horizontal field.

In Figure 5, a more realistic example is shown, where the inclination of the magnetization is $45^{\circ}$. The variations of the magnetic fields for the horizontal boundary $(\alpha=0)$ shown in the leftmost diagram of Figure 5 are similar to the variations shown in Figure 2, where the amount of the jump in the vertical component of the magnetic field is twice as large as that of the horizontal field. As the boundary tilts toward the magnetization direction, the amount of the jump in the vertical field decreases and that in the horizontal field increases. This tendency continues until the dip angle coincides with the inclination of the magnetization, where the vertical field becomes zero throughout the hole. If the dip angle is greater

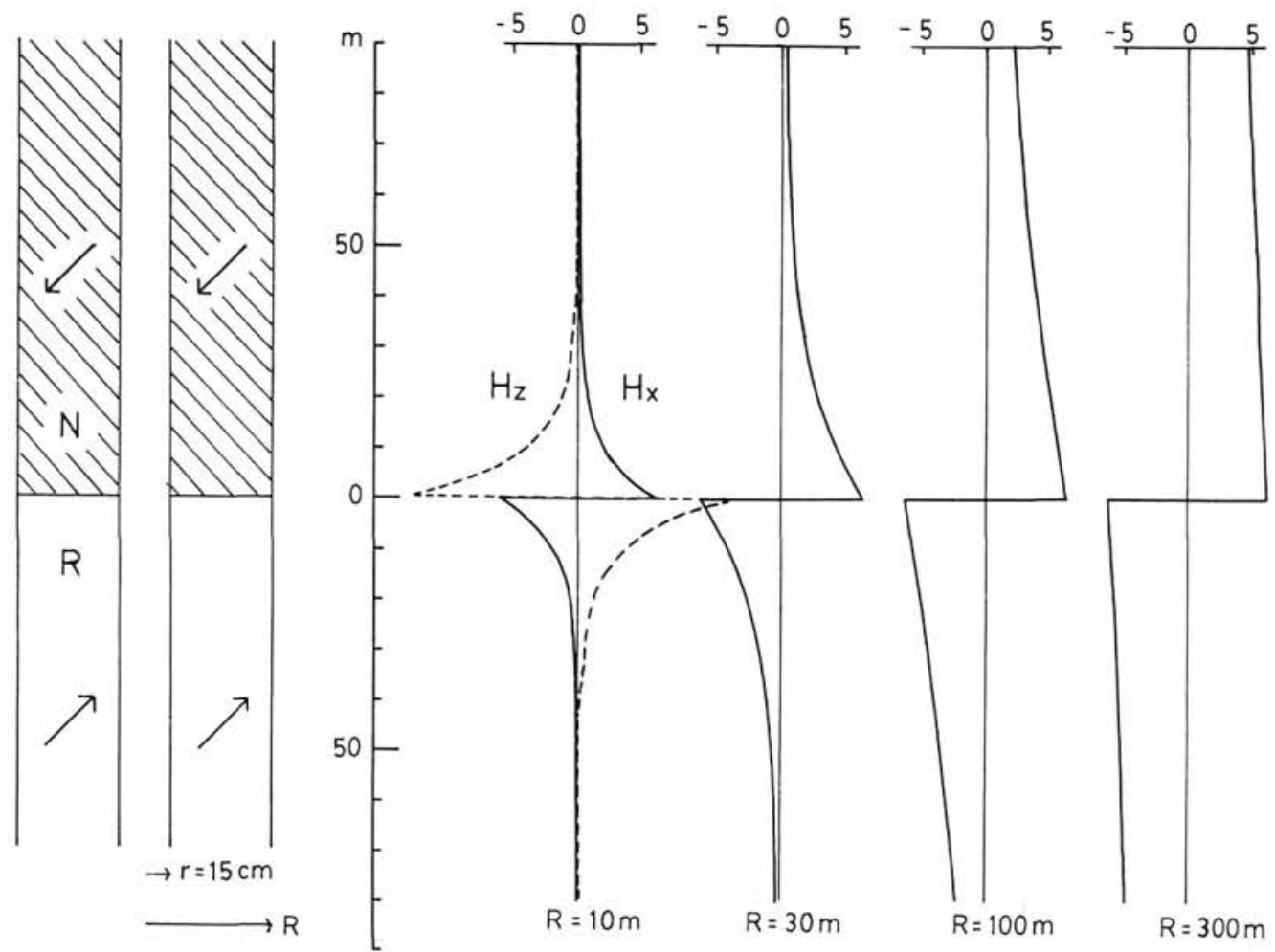

Figure 2. Variation of the vertical $\left(\mathrm{H}_{\mathrm{z}}\right.$, dashed line $)$ and the horizontal $\left(\mathrm{H}_{\mathrm{x}}\right.$, solid line $)$ components of the magnetic field calculated from a circular hole model with a horizontal normal-reverse boundary. The variation of $\mathrm{H}_{\mathrm{z}}$ is shown only for $\mathrm{R}=10 \mathrm{~m}$. In other cases, $\mathrm{H}_{\mathrm{z}}$ is twice the value of $\mathrm{H}_{\mathrm{x}}$ with opposite sign. Unit for the magnetic field is $100 \mathrm{nT} / \mathrm{Am}^{-1}$. 

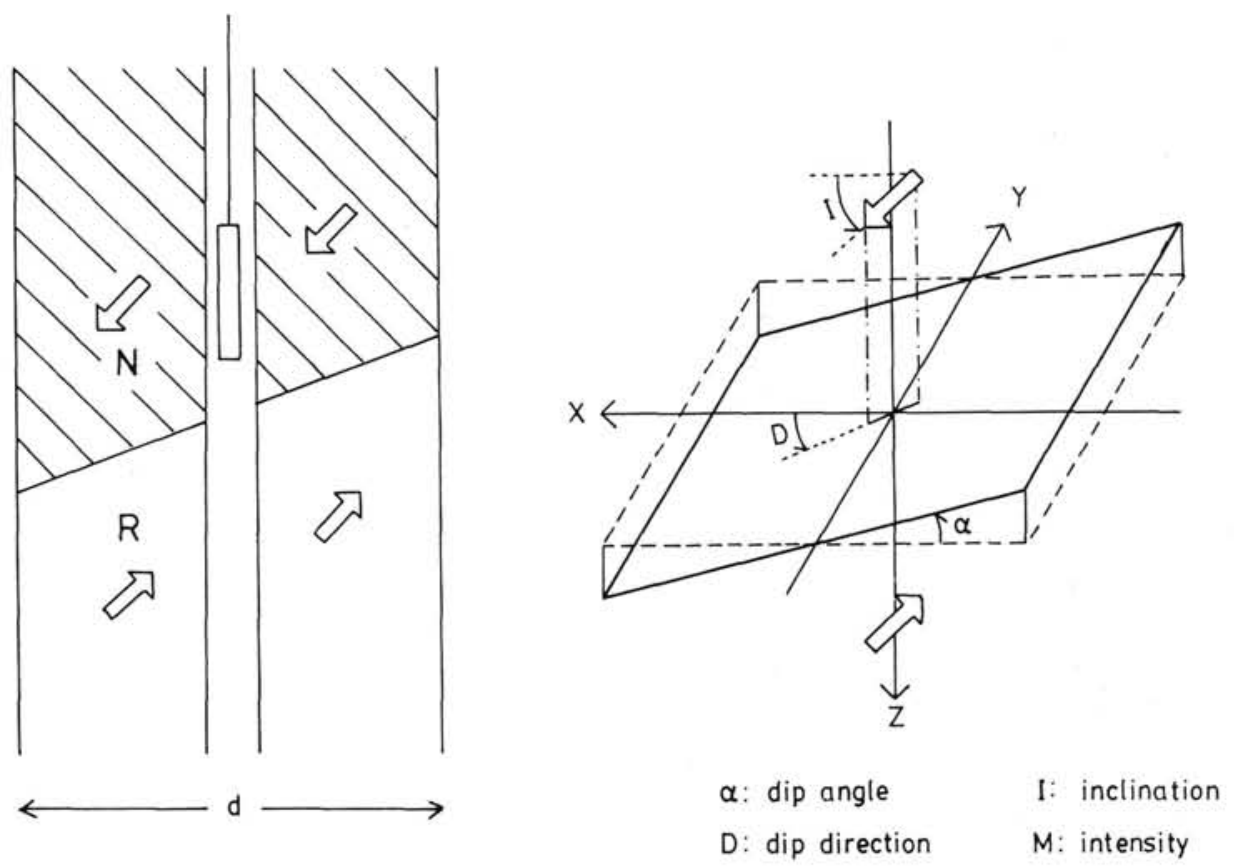

Figure 3. Coordinate system for the tilted boundary model.

than the inclination, the vertical field increases in the opposite direction. The amount of the jump at the boundary in the horizontal and the vertical directions is similar when the dip angle is about $20^{\circ}$, which can explain the observed variation shown in Figure 1. However, the decay rate of the magnetic field in both directions is the same, contrary to the observation.
In Figure 6, the dip angle of the boundary surface is kept constant $\left(30^{\circ}\right)$ and dip directions are varied by steps of $45^{\circ}$. The change affects the shape of the variation of the magnetic field as well as the amount of the jump at the boundary. As shown in Figure 6, the character of the horizontal component of the magnetic field is much more affected by the change of the dip

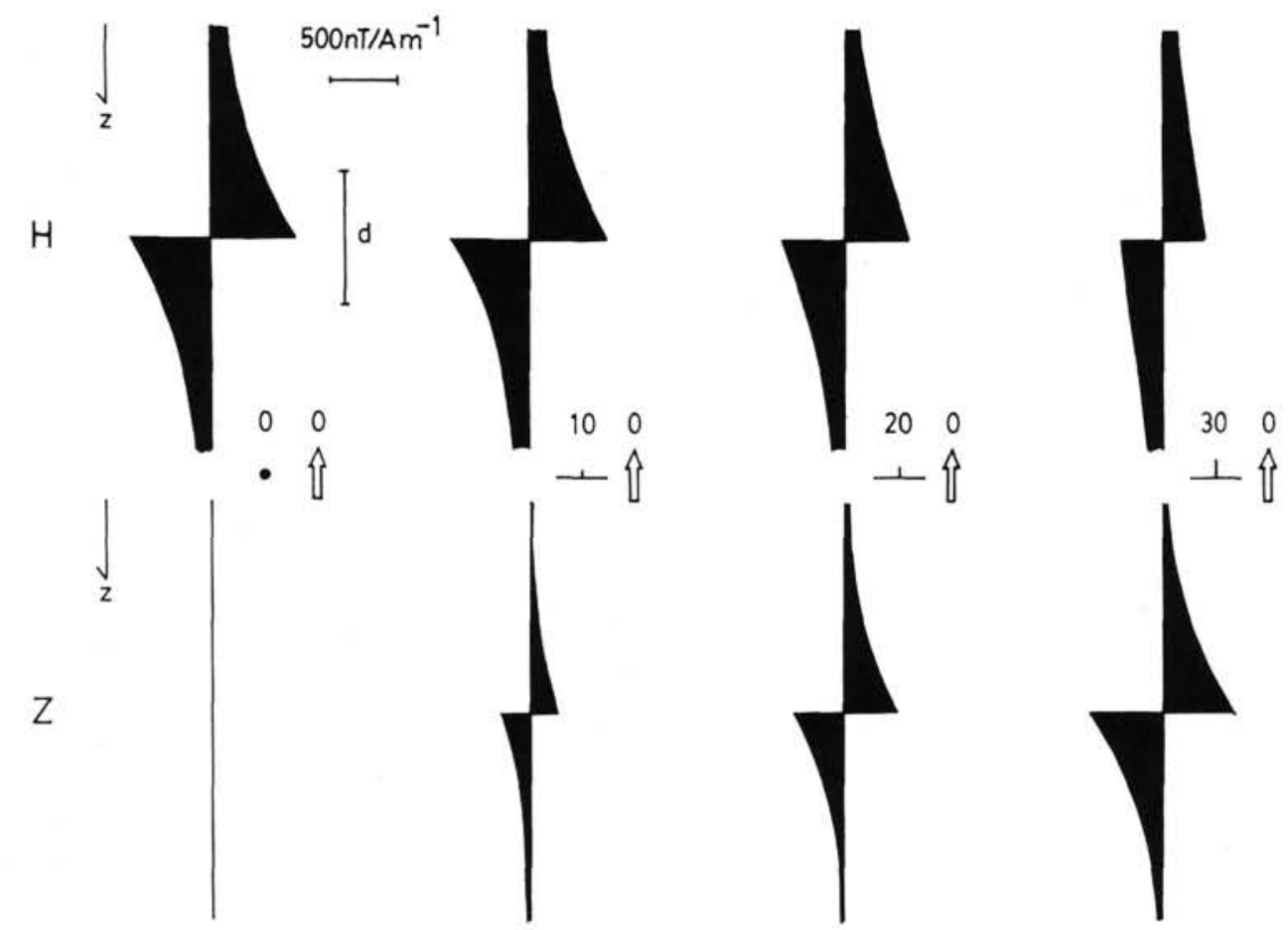

Figure 4. Calculated variation of the vertical $(\mathrm{Z})$ and the horizontal $(\mathrm{H})$ components in cases $\mathrm{I}=0^{\circ}, \mathrm{D}$ $=0^{\circ}$, and $\alpha=0^{\circ}, 10^{\circ}, 20^{\circ}$, and $30^{\circ}$, where $\mathrm{d}$ denotes the horizontal extent of the homogeneously magnetized region around the hole. 

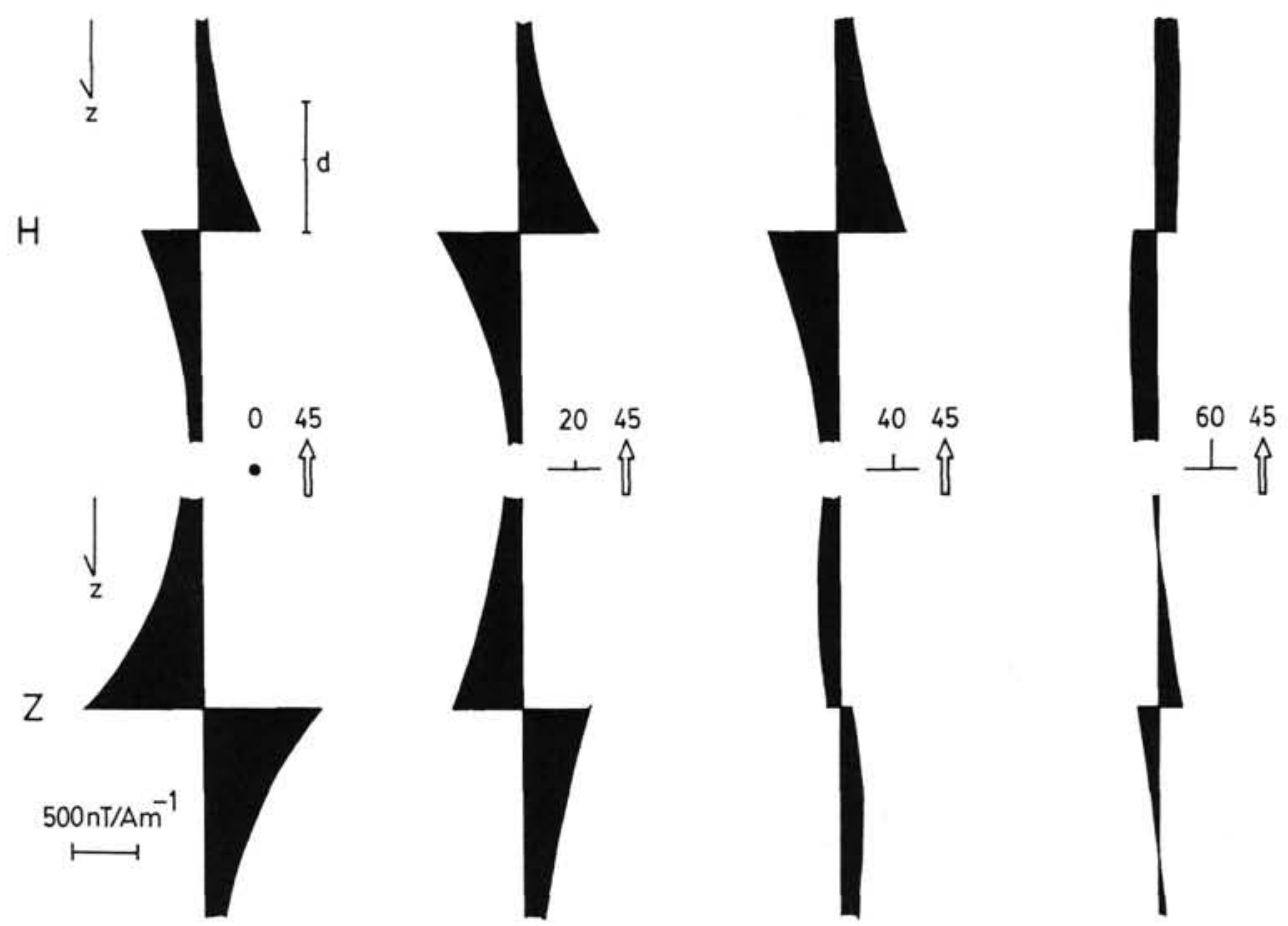

Figure 5. Calculated variation of the magnetic fields for $\mathrm{I}=45^{\circ}, \mathrm{D}=0^{\circ}$, and $\alpha=0^{\circ}, 20^{\circ}, 40^{\circ}$, and $60^{\circ}$.

direction than that of the vertical field. Among the variations shown in Figure 6, the middle one, where the dip direction is perpendicular to the magnetization direction, closely resembles the observed variation of the vertical and the horizontal field. The amount of the jump at the boundary is similar in the both directions, the vertical field on both sides of the boundary slowly decays to zero, while the horizontal field decays more abruptly.
If this model is applied to the observed variation shown in Figure 1 , horizontal extent of the homogeneously magnetized region around the hole is to be estimated around $100 \mathrm{~m}$.

\section{DISCUSSION}

As for the structure of the magnetization in the oceanic crust which is responsible for the magnetic lineation, the
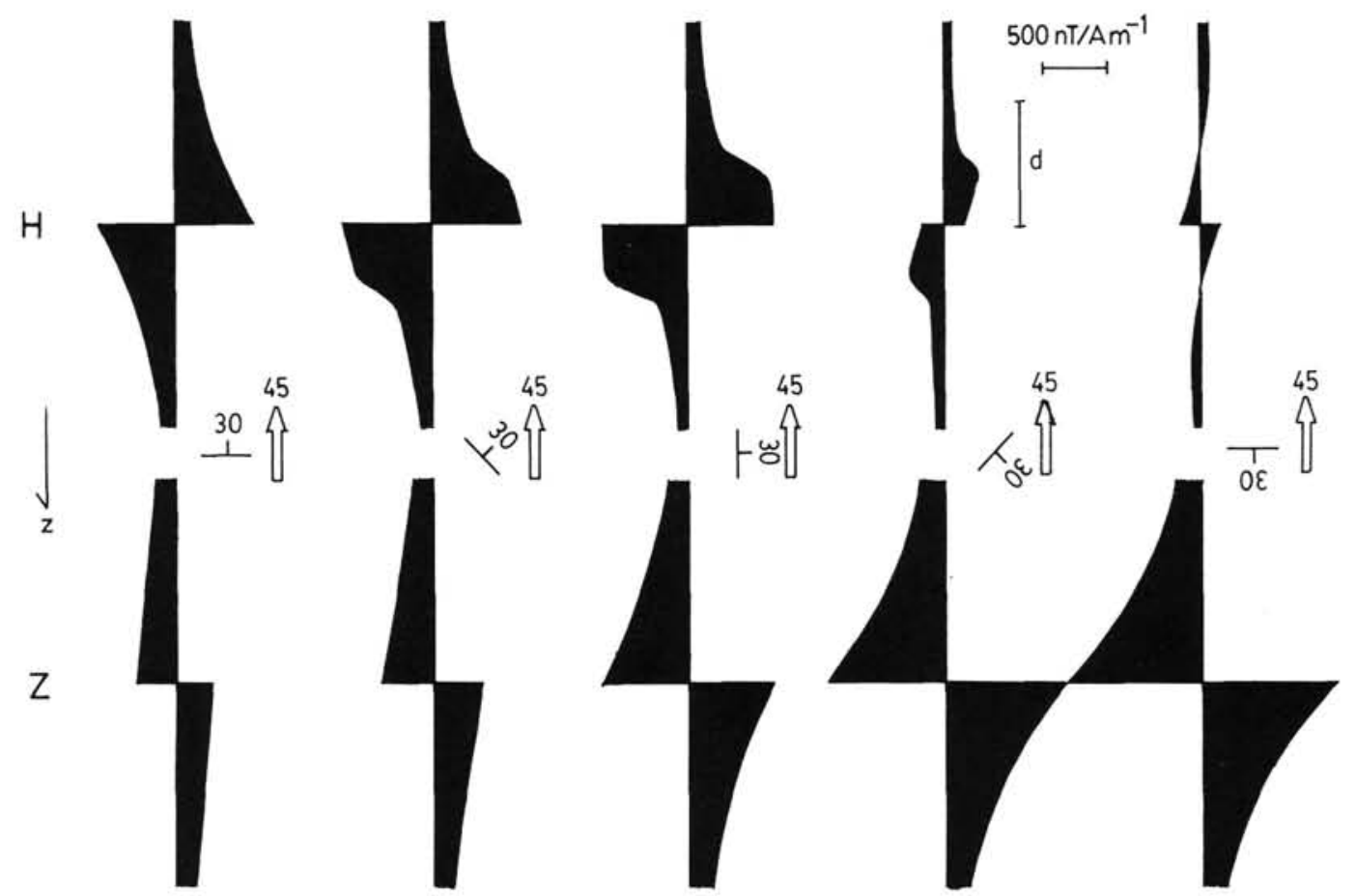

Figure 6. Calculated variation of the magnetic fields for $\mathrm{I}=45^{\circ}, \alpha=30^{\circ}$, and $\mathrm{D}=0^{\circ}, 45^{\circ}, 90^{\circ}, 135^{\circ}$, and $180^{\circ}$. 
original Vine-Matthews hypothesis (Vine and Matthews, 1963) assumed vertical boundaries between the normally and the reversely magnetized section in the oceanic crust. Although the thickness of the magnetized layer responsible for the magnetic lineation varied (see Blakely, 1983, for the tabulation), the vertical boundary had been assumed until the drilling of the oceanic basement of DSDP and ODP revealed a more complicated structure of the upper part of the oceanic crust. In DSDP and ODP holes in the Atlantic Ocean, the magnetization of the basalts is not homogeneous and normally and reversely magnetized sections were observed in a single hole. Hole $395 \mathrm{~A}$ was drilled in the middle of the normal anomaly (Anomaly 4) with the extent of about $10 \mathrm{~km}$. But, only the upper $270 \mathrm{~m}$ is normally magnetized and the lower part is reversely magnetized. In order to explain these observations, we have to assume tilted boundaries. These complicated structures of the oceanic crust have been proposed based on the forward modeling and the measurements using deep-tow instruments and/or submersibles (Schouten and Denham, 1979; Kidd, 1977; Macdonald et al., 1983). However, more direct measurements for the magnetic structure of the oceanic crust are required to establish the structure.

As shown in the present paper, measurements of the three components of the magnetic field within the holes can give new information on the magnetic structure of the oceanic crust. The depth variation of the magnetic field in the hole provides some clues as to the horizontal variation of the magnetization as well as the vertical variation. In the present case, the normal-reverse boundary observed at $260 \mathrm{~m}$ subbottom depth in Hole $395 \mathrm{~A}$ is estimated to be tilted in an east-west direction by about $30^{\circ}$. Unfortunately, the present method cannot discriminate between east and west dipping. But, multiple-hole measurements could be used to estimate the real magnetic structure of the oceanic crust.

\section{CONCLUSION}

Observations of the three components of the magnetic field in Hole 395A revealed the magnetic structure of the basaltic rocks around the hole. The size of the homogeneously magnetized body around the hole is estimated to be about $100 \mathrm{~m}$, and the normal-reverse boundary observed at $260 \mathrm{~m}$ subbottom depth in the hole is tilted in an east-west direction by about $30^{\circ}$.

\section{REFERENCES}

Blakely, R. J., 1983. Statistical averaging of marine magnetic anomalies and the ageing of oceanic crust. J. Geophys. Res., 88: 2289-2296.

Detrick, R. S., Honnorez, J., Bryan, W. B., Juteau, T., et al., 1988. Proc. ODP, Init. Repts., 106/109. College Station, TX (Ocean Drilling Program).

Johnson, H. P., 1978. Paleomagnetism of igneous rock samplesDSDP LEG 45. In Melson, W. G., Rabinowitz, P. D., et al., Init. Repts. DSDP, 45: Washington (U.S. Govt. Printing Office), 387-396.

Kidd, R. G. W., 1977. A model for the process of formation of upper oceanic crust. Geophys. J. R. Astron. Soc., 50:149-183.

Macdonald, K. C., Miller, S. P., Luyendyk, B. P., Atwater, T. M., and Shure, L., 1983. Investigation of a Vine-Matthews magnetic lineation from a submersible: The source and character of marine magnetic anomalies. J. Geophys. Res., 88:3403-3418.

Ponomarev, V. N., and Nechoroshkov, V. L., 1984, Downhole magnetic measurements in oceanic crustal Hole $395 \mathrm{~A}$ on the MidAtlantic Ridge. In Hyndman, R. D., Salisbury, M. H., et al., Init. Repts. DSDP, 78B: Washington (U.S. Govt. Printing Office), 731-719.

Schouten, H., and Denham, C. R., 1979. Modeling the oceanic magnetic source layer. In Talwani, M., Harrison, C. G., and Hayes, D. E. (Eds.), Deep Drilling Results in the Atlantic Ocean: Ocean Crust, Maurice Ewing Ser., vol. 2, Washington (AGU), 151-159.

Vine, F. J., and Matthews, D. H., 1963. Magnetic anomalies over oceanic ridges. Nature, 199:947-949.

Date of initial receipt: 31 Aug 1988

Date of acceptance: 3 April 1989

Ms 106/109B-148 